\title{
Coordenação de aperfeiçoamento de pessoal de nível superior: agente regulador do campo da pós-graduação stricto sensu no Brasil
}

\section{Coordination of improvement of higher education personnel: regulatory officer field of post-graduate studies in Brazil}

\author{
Rogerio Junior Boratim ${ }^{1}$
}

Resumo

O presente artigo tem o propósito de apresentar uma reflexão sociológica sobre a atuação da Coordenação de Aperfeiçoamento de Pessoal de Nível Superior (CAPES) como o agente regulador que institucionalizou o campo da pós-graduação no Brasil junto às Universidades públicas. As premissas metodológicas e teóricas utilizadas sustentam-se na teoria do campo científico de Pierre Bourdieu e procuram demonstrar que a CAPES como ente político vinculado ao governo federal intermediou e legitimou a participação dos docentes-pesquisadores detentores de maior capital simbólico (reconhecimento científico entre os paresconcorrentes), conferindo-lhes a prerrogativa de definir as regras para a avaliação e para o financiamento da Pós-Graduação Stricto sensu. Não obstante, estes legítimos mutuários (dominantes) do campo da pósgraduação, consolidaram um sistema meritocrático amalgamado pelo produtivismo acadêmico, instaurando no âmbito das universidades uma cultura performática que traz a reboque o individualismo, o utilitarismo e a precarização do trabalho e das relações no campo universitário.

Palavras-chaves: Capital simbólico. Produtivismo acadêmico. Avaliação. Precarização.

\begin{abstract}
This paper aims to present a sociological reflection on the role of the Coordination of Improvement of Higher Education Personnel (CAPES) as the regulator that institutionalized the field of postgraduate studies in Brazil with public universities. The methodological and theoretical assumptions underpin the theory of the scientific field of Pierre Bourdieu and seek to demonstrate that the CAPES as a political entity linked to the federal government brokered and legitimized the involvement of the holders of teacher-researchers greater symbolic capital (scientific recognition among peers-competitors ), giving them the prerogative to set rules for the evaluation and funding of post-graduate studies . Nevertheless, these legitimate borrowers (dominant) in the field of post-graduate consolidated merit system amalgamated by one academic productivism, establishing universities within a performance culture that brings the trailer individualism, utilitarianism and the casualization of labor and relations in the university field.
\end{abstract}

keywords: Symbolic capital. Academic productivism. Review. Precariousness.

\footnotetext{
${ }^{1}$ Mestrado em Políticas Públicas da UEM. E-mail: boratim@uel.br
} 


\section{Introdução}

O desenvolvimento científico e tecnológico no Brasil está indissociavelmente vinculado a consolidação de um sistema nacional de pósgraduação stricto sensu (Mestrado/Doutorado) ${ }^{2}$, que desde meados do século XX é orientado e controlado por uma política do governo federal fortemente centralizada em órgãos estruturados a partir de uma perspectiva cientificista e produtivista.

Historicamente o campo cientifico vem sofrendo interferências de outros campos, como do político (órgãos do governo), do econômico (empresas estatais e privadas), do mercado internacional e do social (demandas para resolução de problemas da sociedade). Como a pós-graduação é o campo que tem como capital simbólico à produção do conhecimento científico, das pesquisas básica e aplicada, bem como a formação de recursos humanos especializados, nas últimas décadas passou a ser vista pelo Governo Federal brasileiro como área estratégica para o desenvolvimento científico e tecnológico do país.

Neste contexto de desenvolvimento científicotecnológico, o Estado passou a institucionalizar uma rede de agências de fomento à pesquisa, estimulando e atraindo a elite intelectual do país, que naquele momento organizava-se através dos programas de pós-graduação stricto sensu, centros privados de pesquisa e sociedades científicas (MICELI, 1995).

O cenário no qual se desenrolou o campo científico brasileiro foi delineado por predicados meritocráticos, pois a valoração agregada ao produtor e ao produto da ciência, utilizando as palavras de Pierre Bourdieu, perpassa a "luta pelo monopólio da competência científica" em um campo onde o capital simbólico do dominante equivale à capacidade técnica e poder social (BOURDIEU, 1983, p. 122).

A meritocracia na pós-graduação brasileira está evidenciada não somente pelas características do sistema de avaliação controlado pela Coordenação de Aperfeiçoamento de Pessoal de Nível Superior (CAPES), mas também, nos critérios adotados pelo Conselho Nacional de Desenvolvimento Científico e Tecnológico (CNPq) na distribuição de recursos, que prioriza os pesquisadores considerados produtivos vinculados aos Programas de PósGraduação Stricto sensu com conceito 5 ou superior. Porém deve-se destacar que o critério logrado no mérito acadêmico que fundamenta a estrutura do campo da pós-graduação foi convencionado pelos próprios agentes do campo. Bourdieu (2004, p. 23), assinala que o campo científico é uma estrutura profundamente hierarquizada e pré-estabelecida:

[...] o que comanda os pontos de vista, o que comanda as intervenções científicas, os lugares de publicação, os temas que escolhemos, os objetos pelos quais nos interessamos, etc. é a estrutura das relações objetivas entre os diferentes agentes que são, para empregar ainda a metáfora 'einsteiniana', os princípios do campo. É a estrutura das relações objetivas entre os agentes que determina o que eles podem e não podem fazer. Ou, mais precisamente, é a posição que eles ocupam nessa estrutura que determina ou orienta, pelo menos negativamente, suas tomadas de posição. [...]

As teorias desenvolvidas por Bourdieu demonstram que as estruturas sociais e seus grupos são formados por agentes que participam de um jogo de relações de poder que se legitima no instante em

\footnotetext{
${ }^{2}$ O Parecer CFE No 977/65 traz as seguintes conclusões sobre as características fundamentais dos cursos de pós-graduação stricto sensu: 1) A pós-graduação de que trata a alínea b) do artigo 69 da Lei de Diretrizes e Bases é constituída pelo ciclo de cursos regulares em seguimento à graduação, e que visam a desenvolver e aprofundar a formação adquirida nos cursos de graduação e conduzem à obtenção de grau acadêmico. 2) A pós-graduação, compreenderá dois níveis de formação: Mestrado e Doutorado. Embora hierarquizados, o mestrado não constitui condição indispensável à inscrição no curso de doutorado. 3) $\mathrm{O}$ mestrado pode ser encarado como etapa preliminar na obtenção do grau de doutor ou como grau terminal. 4) O doutorado tem por fim proporcionar formação científica ou cultural ampla e aprofundada, desenvolvendo a capacidade de pesquisa e poder criados nos diferentes ramos do saber.
} 
que há um consenso e quando os agentes do campo reconhecem (muitas vezes de forma inconsciente) o poder do dominante.

O campo da pós-graduação é um destes espaços onde os agentes do campo cientifico (pesquisadores, docentes e discentes) almejam inserir-se, mesmo ocupando posições hierarquicamente diferentes, pois o valor agregado ao campo da pós-graduação é uma construção social ligada a competência e ao reconhecimento.

$\mathrm{Na}$ sequência iremos compreender como a CAPES tornou-se o agente articulador das políticas públicas de pós-graduação, ou seja, como historicamente aglutinou força política e consumou a pós-graduação stricto sensu através da implantação de um sistema de avaliação e financiamento, objetivando as relações do campo.

A CAPES legitimou uma estrutura técnicoburocrática de forma articulada com o corpo de docentes-pesquisadores possuidores de maior capital intelectual dentro do campo da pós-graduação nacional (os detentores das condições simbólicas que os habilitam a estabelecer as regras do jogo), definindo como principal regra balizadora os índices de produção científica, elemento de conversão do capital intelectual em capital econômico, ou melhor, em recursos financeiros para fomento a pesquisa.

Tudo se passa como se os cientistas-pesquisadores que organizam sua carreira e seu trabalho na perspectiva do produtivismo acadêmico são movidos por disposições de crença, acreditam (ou se "iludem") que todo o esforço empreendido para alcançar altos índices de produção científica será convertido em distinção, prestígio e financiamento.

Para o sociólogo francês Bernard Lahire (2005, p. 18) a ilusão é uma disposição de crença que explica em parte o funcionamento do mundo social:

[...] A relação ilusória que qualquer actor pode ter em relação às suas próprias práticas não é um tema sociologicamente muito na moda. Mas a simples consideração das distâncias entre o que os actores dizem sobre o que fazem e o que podemos aprender sobre o que eles fazem através da observação directa dos seus comportamentos, permite pôr em evidência essa ilusão (que, obviamente, faz parte do mundo social e constitui um elemento do seu funcionamento). $[\ldots]$

Veremos que o processo de formação do campo da pós-graduação foi ao longo do tempo incutindo e reproduzindo uma cultura acadêmico-científica identificada com a competitividade, na qual o discurso dos "bem-sucedidos" foi imperativo para legitimar a política de financiamento para os pesquisadores e as instituições exitosas. Logo, o espaço social das universidades que outrora representava (ou imaginava-se) uma congregação de pessoas cultas, foi transformado em arena de disputas dissimuladas e vaidades arbitrárias.

\section{Consolidação de um Sistema Meritocrático de Avaliação da Pós-Graduação Stricto Sensu: Reflexos na Organização das Instituições de Ensino Superior e no Trabalho Docente}

Desde que a CAPES adotou como diretrizes para a política de pós-graduação, o financiamento dos

\footnotetext{
A dissertação, de autoria de Mário José de Souza, produzida no Mestrado Profissional em Políticas Públicas (UEM), citada no referencial bibliográfico do presente trabalho, apresenta resultados que demonstram como a sistemática de incentivo a ciência e tecnologia no Estado do Paraná (Fundo Paraná de Ciência e Tecnologia) segue a dinâmica dos processos meritocráticos de concessão de recursos, na qual as regras a serem seguidas são aquelas dispostas pelo campo científico (teoria de Pierre Bourdieu) e tendem a beneficiar nas instituições de ensino e pesquisa os grupos que acumulam maior capital científico. Com isso: [...] A questão da formulação de políticas públicas na área de ciência e tecnologia é mais complexa do que em outras áreas, pois o grau de exigência dos destinatários é muito grande, diferentemente das demais áreas, ao mesmo tempo em que os mesmos são formuladores, implantadores e avaliadores destas políticas. O poder dos dominantes no campo científico influencia a política de investimentos em ciência e tecnologia, pois seus membros mais influentes defendem o interesse dos grupos e do campo nos quais atuam frente a outras influências decisórias no âmbito do governo estadual. [...] (SOUZA, 2012).
} 
programas e um sistema de avaliação, percebese que as inter-relações destas matrizes colocam o campo num tipo de circuito de disputa cujas regras tendem a favorecer determinados grupos. Coincidentemente, os mutuários beneficiados pela estrutura do campo da pós-graduação brasileira são àqueles agentes que ajudaram a dotar de significado social o campo, tendo como peso e medida o capital científico agregado primeiramente por eles ${ }^{3}$.

O sistema de avaliação da CAPES foi incorporando graus de complexidade e de exigência com o crescimento acelerado e induzido da pósgraduação stricto sensu. A análise temporal desta estrutura revela que o campo científico da pósgraduação tem a dinâmica de regras determinadas pelo acúmulo de capital científico, ou seja, as áreas de avaliação da CAPES, que são compostas por docentes e/ou pesquisadores de reconhecida capacidade científica entre os pares concorrentes do campo, têm consubstanciado quesitos de avaliação de difícil consecução pelos docentes dos Programas de Pós-Graduação das áreas "menos consolidadas" (por exemplo: determinada média de publicação de artigos em periódicos qualificados pela área no triênio da avaliação). Esta condição de definição dos critérios é uma prerrogativa dos dominantes do campo, nesta perspectiva, Bourdieu (1983) apresenta a seguinte análise:

[...] Em todo campo se põem, com forças mais ou menos desiguais segundo a estrutura da distribuição do capital no campo (grau de homogeneidade), os dominantes, ocupando as posições mais altas na estrutura de distribuição de capital científico, e os dominados, isto é, os novatos, que possuem um capital científico tanto mais importante quanto maior a importância dos recursos científicos acumulados no campo.

Tudo parece indicar que, à medida que crescem os recursos científicos acumulados, e que, em conseqüência da elevação correlativa do direito de entrada, elevase o grau de homogeneidade entre os concorrentes, a concorrência científica tende a distinguir-se em sua forma e intensidade daquela que se observava em estados anteriores desses mesmos campos ou em outros campos onde os recursos acumulados são menos importantes e o grau de heterogeneidade mais elevado. [...] (BOURDIEU, 1983, p. 136-137).
Cabe lembrar que o sistema de avaliação da pósgraduação stricto sensu implantado pela CAPES no ano de 1976 já sofreu várias alterações e continua suscetível a elas, isto porque as demandas internas são remodeladas pelo próprio campo ou quando há insurgências de outros campos. Sendo que a força motriz, ou melhor, o dispositivo que alimenta o processo de construção da mesma (avaliação), são as representações ou significações ligadas a qualidade dos produtores de conhecimento (docentes-pesquisadores) e dos respectivos produtos (qualificação de profissionais e produção científica), sem falar que, atualmente, as diretrizes da avaliação apontam para a valorização de mais um fator de mensuração, a projeção dos Programas de Pós-Graduação no cenário internacional.

Deste processo ininterrupto podemos destacar vários momentos, mas pelas características do campo científico, ou seja, por ser uma estrutura que coloca seus agentes em continuum estado de competição, existe a tendência predominante de tornar a avaliação um ritual de exaltação e valorização daqueles que detêm o maior capital acadêmico e de "punição" dos que não tiveram desempenho satisfatório.

Oliveira e Fonseca (2010) destacam que no meio acadêmico há diversos debates sobre os efeitos do caráter "performático, quantitativo e contábil" do atual sistema de avaliação da CAPES, muitos contestam o modelo imposto e apontam os aspectos negativos que interferem no processo de formação dos alunos, na gestão dos programas de pós-graduação e na autonomia das instituições, além de ignorar fatores específicos da trajetória de cada universidade e programa, como por exemplo, as características regionais, a conjuntura econômica e política, enfim, elementos históricos da formação dos pesquisadores-professores e das instituições:

[...] Assim, a avaliação quantitativista, utilitarista e competitiva, nos moldes atuais, implica em alterações nos objetivos, valores e processos educativos em cada instituição e programa de pós-graduação, aliando-se a uma lógica de eficiência e eficácia 
institucional que é, em geral, acentuada por um modelo de avaliação centrado em instrumentos que medem a produtividade institucional, favorecendo a perspectiva do Estado avaliador e regulador, em detrimento da autonomia das instituições, dos programas e do campo científico. Nessa última acepção, a avaliação acaba se restringindo à mensuração da performance, deixando de lado a história, a identidade, a relevância, o projeto acadêmico, a inserção e os compromissos acadêmicos e sociais de cada instituição ou programa. Não leva em conta que a qualidade de um programa de pós-graduação, está, em grande parte, associada à existência de condições socioeconômicas e culturais diferenciadas nas regiões geográficas brasileiras, considerando que o sistema de educação superior é diversificado, segmentado e heterogêneo e que isso resulta em qualidade sempre diferenciada. [...] (OLIVEIRA; FONSECA, 2010, p. 47).

Os referidos autores Oliveira e Fonseca (2010), são categóricos em destacar que o modelo de avaliação da CAPES, fundamentalmente quantitativo e voltado para a valorização de produção intelectual com projeção internacional, não dispõe de critérios condizentes com as distintas realidades dos Programas de Pós-Graduação e com as respectivas áreas de conhecimento, ou seja, a utilização de critérios unificados para mensurar situações díspares favorece "as áreas cientificamente hegemônicas".

O adensamento do campo da pós-graduação induz os agentes dominantes, aqueles que habitam as esferas de poder de deliberação dentro da estrutura legitimada pela CAPES, a redefinir os critérios de avaliação de forma a assegurar a estratificação dos grupos, isto porque se deve manter uma certa heterogeneidade do campo, seguindo a lógica da recompensa (financiamento e reconhecimento acadêmico) para aqueles que se destacam entre os pares concorrentes.

Portanto, dentro do planejamento da política de pós-graduação conduzida pela CAPES, a avaliação tem a função de classificar e alojar os agentes do campo dentro dos diferentes espaços dispostos hierarquicamente e, pelas regras do jogo, cada espaço ocupado está dotado de um valor, ou melhor, de um capital simbólico, determinante na destinação dos bens materiais, para ser mais exato, dos recursos financeiros.

A institucionalização da pós-graduação está basicamente atrelada a pesquisa, desta forma, as diferentes agências governamentais de apoio às atividades de pesquisa (federais e estaduais) atuam com o propósito de estimular e valorizar a produção qualificada (publicada em periódicos com elevado fator de impacto e projeção internacional), intensificando no âmbito do campo acadêmico o clima de competição, que leva os agentes jogadores a adotarem determinadas estratégias.

No âmago desta discussão, referencio trecho do artigo intitulado "O impacto da avaliação no desenvolvimento e na reconfiguração do campo universitário brasileiro”, de Ana Paula Hey e de Afrânio Mendes Catani:

[...] Nesta reconfiguração do campo acadêmico/ universitário, onde tudo se encontra rankeado, a produção assume características peculiares, ao menos nas ciências humanas como um todo: as coautorias, até então muito raras, proliferam; são criadas centenas de periódicos para dar vazão aos artigos escritos pelos professores pesquisadores; eventos científicos ocorrem aos montes, com a inscrição de dezenas de trabalhos - mas com a ausência de parte considerável dos autores; as coletâneas dão o tom, parte delas pagas na íntegra ou em considerável percentual pelos próprios autores; o orientador automaticamente converte-se em, ao menos, coautor da pesquisa ou do trabalho do orientando. [...] (HEY; CATANI, 2010, p. 74).

Inegavelmente, este formato de avaliação fortalece um tipo de política pública que acentua o caráter individualista e utilitarista da atividade de pesquisa, pois deve atender as demandas de uma sociedade cujas bases econômicas estão ancoradas nos processos produtivos.

A educação superior no Brasil não passou despercebida do processo de globalização/ mercantilização imposto pelo livre mercado e capital estrangeiro, as parcerias com entidades 
internacionais (Organização Mundial do Comércio - OMC, Fundo Monetário Internacional - FMI, Banco Mundial, entre outros), intensificadas a partir da metade da década de 1990, com o governo de Fernando Henrique Cardoso, ultrapassaram os "muros" das instituições de ensino superior, no instante que influenciaram sobremaneira as políticas da educação superior implementadas pelo governo federal.

Fonseca e Oliveira (2010) sustentam que o pragmatismo defendido pelas referidas agências internacionais ansiava que o desenvolvimento da educação superior estivesse vinculado ao atendimento das demandas relacionadas aos processos produtivos da economia capitalista, portanto, este ideário balizou muitas das ações induzidas no campo acadêmico pelo governo federal durante o primeiro mandato do presidente Fernando Henrique Cardoso (95-2002):

[...] A partir dos anos de 1990, vêm se impondo pressões para que as universidades atendam às requisições de política científica e de pós-graduação definidas pelas agências brasileiras de fomento e avaliação. A Coordenação de Aperfeiçoamento dos Profissionais de Nível Superior (Capes) e o Conselho Nacional de Pesquisas (CNPq) passaram a requisitar cada vez mais a ampliação e a "qualidade" da pesquisa científica, tecnológica e da inovação, sobretudo aquelas voltadas aos temas considerados estratégicos para a inserção do país no contexto da globalização competitiva. [...] (FONSECA; OLIVEIRA, 2010, p. 114).

Os efeitos do modelo performático da avaliação da CAPES no processo que envolve a rotina docente e discente é muito visível quando examinadas as normas internas constantes nos regulamentos dos Programas de Pós-Graduação, são encontradas disposições legitimadas pelas exigências convencionadas pelas diferentes áreas de avaliação da CAPES, por exemplo, os critérios de credenciamento e descredenciamento de docentes dos Programas levando-se em consideração os indicadores de produção intelectual.
Cabe ressaltar que as disposições e as práticas específicas de cada campo são o resultado do confronto dos agentes no interior do próprio campo e das estratégias utilizadas por cada um ou cada grupo na luta para colocar sua visão, concepção e métodos como os mais adequados e, conseqüentemente, melhorar sua posição e seu capital simbólico.

Apoiados na teoria do campo de Pierre Bourdieu, Hey e Catani (2010, p. 54) apresentam a seguinte definição sobre o campo universitário:

\begin{abstract}
[...] Entendemos por campo universitário o lócus de relações que envolve como protagonistas agentes que possuem a delegação para gerir e produzir práticas universitárias, isto é, uma modalidade de produção consagrada e legitimada. É um espaço social institucionalizado, delimitado, com objetivos e finalidades específicas, onde se instala uma verdadeira luta para classificar o que pertence ou não a esse mundo e onde são produzidos distintos enjeux de poder. As diferentes naturezas de capital e as disposições acadêmicas geradas e atuantes no campo materializam-se nas tomadas de posição, é dizer, no sistema estruturado das práticas e das expressões dos agentes. [...]
\end{abstract}

Com a institucionalização e intensificação das ações reguladas no campo da pós-graduação pelas agências de avaliação e fomento (CAPES, CNPq, FINEP), houve sobremaneira a valorização e projeção dos agentes ligados aos programas de pósgraduação, pois o valor agregado as estes agentes os colocaram em posição de destaque dentro da instituição. O poder simbólico incorporado por este seleto grupo foi se materializando em bens materiais e financeiros, já que a estrutura de fomento a pesquisa organizada pelas referidas agências, beneficia aqueles que detêm os melhores currículos (para Bourdieu, os agentes do campo são classificados pela "propriedade pertinente").

No campo universitário, assim como em qualquer outro, existe um conjunto de "propriedades pertinentes" a ele e a "população dos indivíduos construídos", para Bourdieu o campo possui propriedades pertinentes e 
diferentes graus de posse:

[...] Assim, o trabalho de construção do objeto delimita um conjunto finito de propriedades pertinentes, instituídas por hipótese em variáveis eficazes, cujas variações estão associadas às variações do fenômeno observado, e define assim a população dos indivíduos construídos, caracterizados pela posse em graus diferentes dessas propriedades. Essas operações lógicas produzem um conjunto de efeitos que é preciso explicitar sob pena de registrá-los, sem saber, sob o modo da constatação (o que constitui o erro cardinal do positivismo objetivista). Em primeiro lugar, a objetivação do não objetivado (por exemplo, o prestígio científico) equivale, como se acaba de ver, a um efeito de oficialização, de natureza quase jurídica: assim, o estabelecimento de classes de notoriedade internacional fundadas no número de citações ou a elaboração de um indício de participação no jornalismo são operações totalmente análogas às que realizam, no centro do campo, os produtores de palmarès (lista de alunos premiados). [...] (BOURDIEU, 2011, p. 31).

No campo da pós-graduação do Brasil chama atenção à "inesgotável" capacidade que os agentes dominantes possuem para refinar e redirecionar as regras da competição. Isto porque quando há uma tendência a homogeneização do capital simbólico dos agentes, gera-se um problema para o sistema nacional de pósgraduação, pois necessitaria ampliar seu orçamento a fim de premiar os melhores classificados.

$\mathrm{Na}$ história da avaliação da pós-graduação há um momento muito marcante e que exemplifica esta tendência ao refinamento das normas pelo campo, tratase da mudança da sistemática de avaliação vigente até o ano de 1998, que escalonava a qualificação do Programa de Pós-Graduação num interstício de conceitos de "A" a "E", com prazo de validade por 2 (dois) anos, para um modelo com premissas discricionárias.

Oliveira e Fonseca (2010, p. 40) escrevem:

[...] Na compreensão da CAPES, tornou-se necessário promover alterações no modelo de avaliação, principalmente, porque houve uma "perda do poder discricionário" de classificação, o que resultou em um número muito grande de cursos com conceito $\mathrm{A}$ (excelentes), cerca de $50 \%$, o que não permitia diferenciar os cursos com qualidade inferior. Dentre os principais problemas do modelo anterior foram apontados(as): a) adoção, com referência, de um cenário muito restrito à realidade brasileira; b) superdimensionamento do papel do mestrado e organização de alguns cursos desse nível como verdadeiros pequenos doutorados; c) consagração de um rígido esquema sequencial entre o mestrado e o doutorado; d) consagração dos cursos como unidades de referência para a política de apoio e incentivo à pósgraduação e como base para a estruturação do sistema de avaliação; e) orientação do sistema de pós-graduação quase que exclusivamente para o atendimento das necessidades do mestrado acadêmico; f) valorização e reforço de um modelo rígido de organização da pós-graduação; g) baixo nível de interação entre a pós-graduação e a graduação; h) fortes desequilíbrios inter e intrarregionais e entre as diferentes áreas do conhecimento. [...]

No catálogo publicado pela Coordenação de Aperfeiçoamento de Pessoal de Nível Superior (1996, p. 93) a estatística referente ao número de Cursos de pós-graduação (Mestrado e Doutorado) por conceito, no Brasil, no ano de 1995, é a seguinte:

Tabela 1 - Mestrados no Brasil por conceito no ano de 1995.

\begin{tabular}{c|c|c|c|c|c|c|c|c|c}
\hline Conceitos & A & B & C & CN & CR & D & E & AS & Total \\
\hline Brasil & 426 & 388 & 171 & 106 & 19 & 30 & 14 & 5 & 1159 \\
\hline
\end{tabular}

Fonte: Coordenação de Aperfeiçoamento de Pessoal de Nível Superior (1996). 
Tabela 2 - Doutorados no Brasil por conceito no ano de 1995.

\begin{tabular}{c|c|c|c|c|c|c|c|c|c}
\hline Conceitos & A & B & C & CN & CR & D & E & SA & Total \\
\hline Brasil & 271 & 195 & 43 & 94 & 2 & 7 & 3 & 1 & 616 \\
\hline
\end{tabular}

Fonte: Coordenação de Aperfeiçoamento de Pessoal de Nível Superior (1996).

De fato, a classificação apresentada pela CAPES (1996), evidencia que a estrutura de avaliação (regras dispostas para a competição no campo) colocava o capital simbólico dos agentes dominados próximo ao dos dominantes, pois, de um total de 1.159 cursos de mestrados, $814(70 \%)$ estavam conceituados em A e B e os demais (30\%) distribuídos pelos conceitos inferiores, quanto aos cursos de doutorado, observa-se uma proporção semelhante (75\% enquadrados nos conceitos A e B).

Com a implantação do novo modelo de avaliação, o campo da pós-graduação, que até então vinha concentrando a maioria dos cursos em 2 (dois) grandes blocos, os do conceito "A" e do conceito "B", foi submetido a um processo de descompactação e reclassificação, mensurado por quesitos correspondentes aos pressupostos de qualidade, produtividade e inserção internacional, quesitos estes, que restabeleceram graus de diferenciação entre os agentes do campo ${ }^{4}$.

Quanto ao novo modelo de avaliação implantado, observa-se que o objetivo principal foi redimensionar a representação do capital simbólico dos agentes do campo da pós-graduação, ou seja, com o crescimento do número de cursos e, conseqüentemente, de agentes no campo, as regras que numa fase inicial atendiam as expectativas $\mathrm{e}$ interesses dos dominantes, tornaram-se generalistas e possibilitaram a homogeneização, principalmente, nos blocos que congregavam os cursos com conceito "A" ou "B".

Diante de tais circunstâncias, a partir de 1998, a CAPES implantou uma avaliação formatada para restabelecer o "poder discricionário" da análise e julgamento, para tanto, inseriu novos quesitos e

Para exemplificar o refinamento dos critérios de avaliação do novo modelo instituído pela CAPES, o Documento de Área 2009, referente à avaliação do triênio 2007/2009, da área de Sociologia, definiu como indicadores para a produção intelectual de programas com perfil de conceitos 6 e 7, o seguinte: "Produção científica com inserção internacional: compreende a publicação de resultados de pesquisa, sob a forma de artigos em periódicos científicos, livros e capítulo de livros qualificados, com destacadas proporção e média por docente nos estratos A1, A2 e B1 do Qualis da Área (periódicos). A diferença entre os conceitos 6 e 7 é alcançada por dois critérios: a) proporção do corpo docente com produção científica com inserção internacional; b) média dessa produção bibliográfica por docente ano. Consolidação e liderança nacional: $\mathrm{O}$ atendimento a este item requer que o corpo docente do programa elegível para os conceitos 6 e 7 demonstre participação em: a) convênios e intercâmbios ativos firmados com instituições estrangeiras de reconhecido prestígio científico, em regime de reciprocidade e com divulgação no exterior; b) programas institucionais de cooperação internacional exigindo missões bilaterais de trabalho; c) conferências, mesasredondas, organização de grupos de trabalho e grupos de pesquisa em eventos científicos internacionais de grande relevância para a área; d) promoção de eventos científicos internacionais; e) prêmios internacionais (com láurea e/ou como participação em júris internacionais); f) consultorias e organismos internacionais; g) comitês editoriais e como pareceristas de periódicos internacionais; h) redes internacionais de pesquisa com publicação de resultados; i) corpos diretivos em associações científicas internacionais de grande relevância para a área; j) oferta de cursos e colaboração em atividades de ensino em instituições de reconhecido nível de excelência no exterior; 1) estágios de formação pós-doutoral no exterior; m) obtenção de bolsas de pesquisa ou financiamento de agências internacionais." 
pesos para os elementos considerados fundamentais no desenvolvimento da pós-graduação. Oliveira e Fonseca (2010, p. 40) explicam que:

[...] Na nova sistemática de avaliação, a classificação passou a ser composta por sete níveis de conceitos - de 1 a 7, sem frações, observadas as seguintes determinações: a) Conceito 6 e 7 - exclusivos para programas que ofereçam doutorado com nível de excelência, desempenho equivalente ao dos mais importantes centros internacionais de ensino e pesquisa, alto nível de inserção internacional, grande capacidade de nucleação de novos grupos de pesquisa e ensino e cujo corpo docente desempenhe papel de liderança e representatividade na respectiva comunidade; b) Conceito 5 - alto nível de desempenho, sendo esse o maior conceito admitido para programas que ofereçam apenas mestrado; c) Conceito 4 - bom desempenho; d) Conceito 3 - desempenho regular, atende o padrão mínimo de qualidade exigido; e) Conceitos 1 e 2 - desempenho fraco, abaixo do padrão mínimo de qualidade requerido. [...]

Com a reconfiguração do sistema de avaliação (iniciada em 1998), ocorreu um processo de alteração das disposições do campo, sendo que os efeitos são visíveis, basta analisar a atual conjuntura do sistema nacional de pós-graduação, mais especificamente, a distribuição dos Cursos pelos conceitos:

Tabela 3 - Cursos e Conceitos no ano de 2013.

\begin{tabular}{c|c|c|c|c|c}
\hline CONCEITO & $\begin{array}{c}\text { Total de } \\
\text { Cursos } \\
\text { por } \\
\text { Conceito }\end{array}$ & $\begin{array}{c}\text { Percentual } \\
\text { de Cursos } \\
\text { p/Conceito }\end{array}$ & $\begin{array}{c}\text { Mestrado } \\
\text { Acadêmico }\end{array}$ & Doutorado & $\begin{array}{c}\text { Mestrado } \\
\text { Profissional }\end{array}$ \\
\hline 3 & 1.661 & $30,93 \%$ & 1.225 & 45 & 391 \\
\hline 4 & 1.967 & $36,62 \%$ & 949 & 923 & 95 \\
\hline 5 & 1.103 & $20,54 \%$ & 535 & 539 & 29 \\
\hline 7 & 405 & $7,54 \%$ & 201 & 204 & 0 \\
\hline $\begin{array}{c}\text { Total de } \\
\text { Cursos }\end{array}$ & $\mathbf{5 . 3 7 0}$ & $\mathbf{9 9 , 9 8 \%}$ & $\mathbf{3 . 0 2 7}$ & $\mathbf{1 . 8 2 8}$ & $\mathbf{5 1 5}$ \\
\hline
\end{tabular}

Fonte: Coordenação de Aperfeiçoamento de Pessoal de Nível Superior (2013).

A análise do quadro confirma que a classificação dos Cursos numa escala de conceito variável de 3 a 7 apresenta um número limitado de cursos nos extratos 6 e $7(11,89 \%)$, ou seja, tratam-se de núcleos de acesso restrito e, segundo critérios definidos pelos agentes dominantes do campo, são destinados aos Programas de Pós-Graduação com elevado capital científico. Sendo que as áreas de avaliação da CAPES a cada ciclo de avaliação tendem a elevar as exigências de entrada para os referidos extratos.
O campo da pós-graduação está hierarquizado em uma estrutura consolidada por uma política nacional de pós-graduação fundamentada na classificação dos agentes através de indicadores quantitativos de produção. Portanto, o seu sistema de avaliação e financiamento está correlacionado com o mérito e a distinção (competência científica). Assim, os agentes dominantes do campo, aqueles que ocupam o "topo da pirâmide", rankeados como os mais produtivos, tendem a consumar as representações/disposições que lhes 
são mais favoráveis e ao campo.

Dentre as disposições do campo da pósgraduação há mais uma particularidade, tratase da prerrogativa da arbitragem por parte dos "legítimos" juízes do campo, agentes dominantes que se encontram numa condição confortável, pois legislam e julgam conforme os interesses dos grupos que representam e, no caso da pós-graduação brasileira, o campo ganhou legitimidade e autonomia ao compactuar com as diretrizes reguladoras de órgãos do governo federal (CAPES e CNPq).

Nesta linha de pensamento Bourdieu (1983, p. 130) escreve:

[...] Tanto no campo científico quanto no campo das relações de classe não existem instâncias que legitimam as instâncias de legitimidade; as reivindicações de legitimidade tiram sua legitimidade da força relativa dos grupos cujos interesses elas exprimem: à medida que a própria definição dos critérios de julgamento e dos princípios de hierarquização estão em jogo na luta, ninguém é bom juiz porque não há juiz que não seja, ao mesmo tempo, juiz e parte interessada.

Vemos, assim, a ingenuidade da "técnica dos juízes a que recorre comumente a tradição científica para definir as hierarquias características de um campo determinado: hierarquia dos agentes ou das instituições - as universidades dos EUA; hierarquia dos problemas, domínios ou métodos; hierarquia dos próprios campos etc. e, a mesma filosofia ingênua da objetividade que inspira o recurso a "especialistas internacionais". Como se a posição de observadores estrangeiros pudesse colocá-los ao abrigo dos parti pris e das tomadas de posição num momento em que a economia das trocas ideológicas conhece tantas sociedades multinacionais. E, ainda, como se suas análises "científicas" do estado da ciência pudessem ser outra coisa que não a justificação, cientificamente mascarada, do estado particular da ciência ou das instituições científicas com o qual compactuam. [...]

Amparados no livro "Trabalho intensificado nas federais: pós-graduação e produtivismo acadêmico" de Valdemar Sguissardi e João dos Reis Silva Júnior (2009), Silva e Silva Junior (2010) abordam a intensificação do produtivismo acadêmico dentro de um processo de naturalização do trabalho para dissimular interesses pessoais. Neste contexto, os docentes-pesquisadores em sua dimensão subjetiva, são induzidos a reproduzir um sistema de movimento teleológico (justificado pelas causas finais) imposto pelo Estado. Para cumprir tal finalidade, os docentes-pesquisadores alimentam-se (alienam-se) do que os autores classificam de sociabilidade produtiva: "[...] sociabilidade produtiva, produtora e reprodutora de relações de trabalho com base em uma falsa solidariedade, na qual o coletivo é referido tão somente como elemento necessário para que os projetos individuais não sofram prejuízos, sendo o elemento grupal mero assessório, por isso falso." [...] (SILVA; SILVA JÚNIOR, 2010, p. 228).

O fato é que o produtivismo acadêmico tornouse um valor e uma prática imperativa no trabalho docente e no planejamento das universidades públicas, porém, desencadeou determinados fenômenos em seu interior. Um deles é a desumanização das relações de trabalho, processo pelo qual o trabalhador é submetido a uma série de práticas que individualizam sua rotina e deteriora as relações sócio-institucionais e familiares, já que o ritmo alucinante a que é submetido roubalhe o tempo da família e do lazer, expondo-o a doenças oportunistas que agem diante de um quadro de precarização da saúde do indivíduo.

A mente e o corpo destes "operários da ciência" tendem a sucumbir diante das condições impostas pelo produtivismo acadêmico:

[...] O mal instalado na saúde do professor é a contraface do mal instalado na universidade, nas suas potencialidades críticas e transformadoras que tendem a ser arrefecidas senão sufocadas pelas políticas de produção acadêmico-científica e de avaliação - principal instrumento para a consolidação no cotidiano da ideologia do produtivismo acadêmico, com graves conseqüências para professores, alunos, gestores e funcionários. [...] (SILVA; SILVA JÚNIOR, 2010, p. 236). 
Mas aqueles que não concordam com os ditames e a pressão do produtivismo e trabalham numa perspectiva temporal mais independente, ou seja, desvinculada do "controle e regulação" da produção científica em ritmo da economia capitalista, tendem a ficar "desajustados" ou até mesmo "marginalizados" dentro das relações de trabalho desta universidade reformada pelo Estado.

Nota-se que a perspectiva da performance, como regra de muitos campos e, em especial, do campo da pós-graduação, tem assumido cada vez mais um perfil expositivo, pois ao término de cada ciclo de avaliação, sentencia e expõe o professor perante o seu público (conjunto de agentes), classificando-o como produtivo ou improdutivo conforme a produção apresentada no período.

\section{Considerações Finais}

Sabemos que o Sistema Nacional de PósGraduação caracteriza-se como uma política pública consolidada, não obstante, não podemos ser coniventes com as distorções que impactam negativamente nas relações dos agentes e nas estruturas envolvidas. Encontramos um vasto referencial que analisa as transformações e os efeitos negativos no âmbito das instituições de ensino superior desde que o conhecimento científico passou a figurar na agenda das políticas públicas.

Atualmente vemos ocampocientífico subjugado às demandas do produtivismo acadêmico e os docentes em meio há uma competição frenética, não havendo espaço para relações altruístas. Assim, a universidade tornou-se um ambiente onde os vínculos foram deteriorados pelo individualismo e o trabalho docente planejado e objetivado para cumprir indicadores de produção impostos pelos dominantes nos instrumentos de controle e avaliação.
O perfil desta universidade reformada para a pós-graduação tem sido garantir a formação de jovens doutores em larga escala e em curto espaço de tempo, sem, no entanto, perceber que estes profissionais foram treinados para publicar e que muito provavelmente, a ausência de experiência adquirida em situações reais do trabalho empobrecerão a formação dos seus futuros alunos.

Cabe lembrar que a sistemática de avaliação da CAPES, que dimensiona quantitativamente e qualitativamente o capital acumulado por um Programa de Pós-Graduação durante o período avaliado, é uma prática legítima e aceita de forma geral pelos agentes do campo, pois o ingresso de qualquer agente pressupõe a tácita concordância com os critérios dispostos, bem como a posição designada inicialmente aos recém chegados.

No entanto, a análise sociológica do campo da pós-graduação procurou desmistificar as representações que naturalizam a competição dentro do campo científico (e da pós-graduação), bem como os processos de distinção que levam os agentes a pensarem que são melhores em relação aos outros. Compartilhando com o pensamento de Bourdieu (2004, p. 60-61) o esforço da sociologia da ciência deve estar relacionado com propostas normativas que visam contribuir com a divisão do trabalho científico dentro de um projeto construído coletivamente, integrando e articulando as diferentes funções numa perspectiva política democrática. Faz-se necessário superar a estrutura mental das classificações que levam os agentes a agirem de forma individualista, desagregadora e dissimulada.

Enfim, A universidade não deveria ser tratada como um o locus de disputas de poder e violência simbólica, mas sim um espaço socialmente construído pela diversidade de pensamentos e atitudes, com o objetivo comum de respeito ao outro e a formação de civilidade, independentemente da posição na hierarquia disposta. 


\section{Referências}

BOURDIEU, P. Homo academicus. Tradução de Ione Ribeiro Valle e Nilton Valle. Florianópolis: EDUFSC, 2011.

. O campo científico. In: ORTIZ, Renato. (Org.). Pierre Bourdieu: sociologia. São Paulo: Ática, 1983. p. 122-155.

- Os usos sociais da ciência: por uma sociologia clínica do campo científico. São Paulo: EDUNESP, 2004.

\section{COORDENAÇÃO DE APERFEIÇOAMENTO} DE PESSOAL DE NÍVEL SUPERIOR (CAPES). Diretoria de Avaliação. Situação da pósgraduação: 1995. Brasília, 1996.

FONSECA, M.; OLIVEIRA, J. F. A avaliação da pós-graduação e o seu impacto no trabalho acadêmico dos professores brasileiros. In: OLIVEIRA, J. F.; CATANI, A. M.; FERREIRA, N. S. C. (Org.). Pós-graduação e avaliação: impactos e perspectivas no Brasil e no cenário internacional. Campinas: Mercado de Letras, 2010.

HEY, A. P.; CATANI, A. M. O impacto da avaliação no desenvolvimento e na reconfiguração do campo universitário brasileiro. In: OLIVEIRA, J. F.; CATANI, A. M.; FERREIRA, N. S. C. (Org.). Pósgraduação e avaliação: impactos e perspectivas no Brasil e no cenário internacional. Campinas: Mercado de Letras, 2010.

LAHIRE, B. Patrimônios individuais de disposições: para uma sociologia à escala individual. Sociologia, Problemas e Práticas, Oeiras, n. 49, p. 11-42, set. 2005.

MICELI, S. O cenário institucional das ciências sociais no Brasil. In: MICELI, S. (Org.). História das ciências sociais no Brasil. São Paulo: Sumaré, 1995.

OLIVEIRA, J. F. O.; FONSECA, M. A pósgraduação brasileira e o seu sistema de avaliação. In: OLIVEIRA, J. F.; CATANI, A. M.; FERREIRA, N. S. C. (Org.). Pós-graduação e avaliação: impactos e perspectivas no Brasil e no cenário internacional. Campinas: Mercado de Letras, 2010.
SGUISSARDI, V.; SILVA JÚNIOR, J. R. Trabalho intensificado nas federais: pós-graduação e produtivismo acadêmico. São Paulo: Xamã, 2009.

SILVA, E. P.; SILVA JÚNIOR, J. R. Estranhamento e desumanização nas relações de trabalho na instituição universitária pública. Revista HISTEDBR On-Line, Campinas, v. 10, n. 38e, p. 223-238, ago. 2010.

SOUZA, M. J. Políticas públicas para o campo cientifico: um estudo sobre o fundo Paraná de ciência e tecnologia. 2012. 103f. Dissertação (Mestrado Profissional em Políticas Públicas) Universidade Estadual de Maringá, Maringá, 2012. 